\title{
Conceptual Metaphor Theory \\ Cannot be Just Conceptual
}

Šárka Havlíčková Kysová

Zoltán Köveces. Extended Conceptual Metaphor Theory. Cambridge University Press, 2020. ISBN 9781108490870.

Forty years after the publication of the pivotal work on conceptual metaphor theory (hereafter CMT) The Metaphors We Live By (LAKOFF and JOHNSON 1980), Hungarian linguist Zoltán Kövecses publishes the results of his thorough elaboration of that theory. His book Extended Conceptual Metaphor Theory (2020) provides an overview of the main concepts and terminology of CMT, reviews the main developments in its (as yet short) history, and even tries to connect the theory to another mainstream trend of contemporary cognitive linguistic approach - conceptual blending theory (hereafter CBT) developed since the 1990s and introduced systematically by Mark Turner and Gilles Fauconnier in their book The Way We Think (2002). Since the publication of the founding works both theories have been elaborated on by many authors discussing the creative process of the human mind and our conceptualizations of the world we live in and interact with. Kövecses has already published several books and articles on the topic focussed either on methodology itself (KÖVECSES 2010) or on more specialised topics connected to a particular field of human experiences. The latter area can be represented by his longterm interest in conceptualization and manifestation of our emotions (KÖVECSES 2000). In the present book he follows up some of his earlier considerations, especially the role of context in conceptualization of our experiences (KÖVECSES 2015).

In his book Kövecses focuses not only on our "unconscious" metaphorization of experiences in everyday life but he also analyzes less common and more special experiences that can be perceived as somehow extraordinary, i.e. usually characterized as artistic. To use Raymond Gibbs' words (borrowing the title of his book The Poetics of Mind, 1994), he focuses on the topic/ question of how poetic our mind is when finding itself in a poetic situation. Kövecses examines the experiences from fine arts, poetry and even metaphoric manifestations expressed in reviews and comments appearing on tourist websites. This focus on everyday experiences that are perceived as particular is one of Kövecses's "extensions" of the CMT. Another, perhaps more substantial expansion lies in his emphasis on context. Kövecses provides a multilevel approach to metaphor by including the role of context and our (previous) experience in our conceptualisation of a new experience. Further, he discusses metonymy as a possible stage of development and a constituent of metaphor etc.

It appears that Kövecses aims mainly at systematizing, interconnecting and organizing the up-to-date acquired knowledge and concepts of the CBT and CMT into a unified system. The core of Kövecses's "united" CBT-CMT theory lies in 
dealing with schematicity of conceptual levels on the one hand and their specificity on the other. Kövecses's approach is based particularly on four concepts arranged (in his theory) according to the degree of their complexity: image schemas (as the least complex), conceptual domains, frames, and mental spaces (as the most complex). According to Kövecses these concepts are taken into play in cognitive processing of every experience. In his system, the image schemas are more general concepts, preconceptual structures with meaningful and highly schematic gestalts. They are coherent patterns of analogical structures which include only a few parts (e.g. CONTAINER, EXTENSION, PART-WHOLE, OBJECT etc.). They create domains, i.e. coherent conceptual areas that make it possible to characterize semantic units (e.g. PATH, BODY, BUILDING). Next, frames are less schematic and more specific than domains. They elaborate on particular aspects of a domain's matrix. For example, the domain BODY can be understood as developed by various frames as PERCEPTION, DIGESTIVE PROCESSES, PHYSICAL EXERCISES etc. The higher degree of specificity of the frames can be demonstrated on the metaphorical expressions, such as "to digest the idea", to perform a "mental exercise" etc., where a particular frame helps us to conceptualize an experience (e.g. a way/effort of processing of a new idea). These three concepts operate on an "offline level", as Kövecses claims. The distinction between "offline" and "online" makes another part of his approach. Image schemas, domains and frames are considered as independent of the actual situation.

The fourth element of this systematization is mental space, the term connected and elaborated mostly in CBT. Mental spaces are understood as most complex concepts. In Kövecses's approach, the mental space level of conceptualization is dependent on a specific situation of communication, or in Langacker's terms "current discourse space" (LANGACKER 2008). Unlike the three above-mentioned concepts, mental spaces operate "online", but have their basis in the "offline" levels. Mental spaces are particular "formations" constructed - as we think and speak - for the purpose of understanding and acting in particular, actual situations. They are connected to our schematic longterm memory, which can be represented by common everyday experience, such as (the frame of) going on a path.

Kövecses also discusses connections between these four concepts characterizing other aspects of their operation regarding their relationship to actual contexts and the cognitive abilities of human beings. He explains that image schemas operate on a sub-individual level while domains and frames on a supra-individual one. The processes in mental spaces are based on an individual level. This systematization/division serves Kövecses as a basis for his discussion of the role of context in our metaphorical thinking. The understanding of mental spaces as concepts working on individual level in an actual situation helps him to emphasize the role of context - usually rather neglected by CMT. Since "[c]ontext [...] can provide conceptualizers" (113), Kövecses argues for a broad conception of context in metaphorical conceptualization - one that covers our cognitive interaction with various elements and properties of the situation of discourse, the discourse itself, the conceptual-cognitive 
background, and the body of the speaker and hearer. (115)

According to his approach, our interaction with the world can be characterized by four distinct, yet interconnected types of context: situational, discourse, concept-cognitive, and bodily contexts (115).

It seems that from this point of view Kövecses crosses the borders that cognitive linguists often hesitate to pass while studying "poetics" of mind without actually touching upon the topic from the field of art, where the process of meaning construction (and also its perception) is deliberately a poetic experience. Kövecses deals with the metaphor as both a product and process of our cognitive apparatus. However, even though he analyzes works of art - mostly visual and textual experiences (a painting, a poem) - he doesn't provide deeper analysis of more complex pieces of art, such as a film or a piece of theatre. The reason is understandable; his expertise lies mostly in linguistics and the aim of the book is obviously not to provide complex analyses going too far from this field of the author's expertise.

Forty years since the beginning of the conceptual metaphor theory enterprise, we are finally moving further from the field of linguistics. If our minds are "poetic" we should not exclusively focus on our mind's hidden "poetic" capacities. We need to study more thoroughly the deliberate metaphorization in our mind. For we think metaphorically not only because we do/must but also because we want to.
Kövecses supports this view by introducing the context into CMT. In doing this he makes - by that extension - CMT more complex. In seemingly sacrificing the plainness of CMT he brings the theory back to human life, closer to it, and, I think, he also allows a further developing cognitive approach to art.

Kövecses's new treatise on metaphor is well written and provides a clear but not superficial overview of the main concepts of cognitive approach to metaphor. His approach can be also characterized as a matured look back on the up-to-date effort in the field of conceptual metaphor studies, maybe even as a confession admitting to the co-author's perception of the theory forty years on. In this point the book can be understood as Kövecses's own way of meta-conceptualization within the CMT. At the same time, it could serve as an elaborate introduction to a novice interested in the CMT, offering him or her an experienced, evaluative outlook on the topic.

Kövecses claims that "conceptual metaphors cannot and should not be linked to a single conceptual structure, such as frames or domains" and that "conceptual metaphors are complexes of all four of these at the same time" (90). He characterizes this approach as "multilevel view" of metaphor (90) and concludes that "[c]onceptual metaphor theory cannot simply be just conceptual" (177), as a theatre studies scholar would certainly agree. 


\section{Bibliography}

FAUCONNIER, Gilles and Mark TURNER. 2002. The Way We Think: Conceptual Blending and the Mind's Hidden Complexities. Basic Books, 2002.

GIBBS, Raymond W. 1994. The Poetics of Mind. Figurative Thought, Language, and Understanding. Cambridge University Press, 1994.

KÖVECSES, Zoltán. 2000. Metaphor and Emotion. Cambridge University Press, 2000.
KÖVECSES, Zoltán. 2010. Metaphor: A Practical Introduction. Oxford University Press, 2010.

KÖVECSES, Zoltán. 2015. Where Metaphors Come From. Reconsidering Context in Metaphor. Oxford University Press, 2015.

LAKOFF, George and Mark JOHNSON. 1980. Metaphors We Live By. Chicago/London: University of Chicago Press, 1980. 